\title{
Anatomic correction of Ebstein anomaly
}

\author{
Qingyu $\mathrm{Wu}, \mathrm{MD}$, and Zhixiong Huang, MD, Beijing, China
}

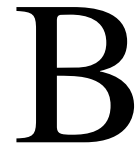

etween December 1997 and February 2001, 23 consecutive cases of Ebstein anomaly underwent anatomic correction.

\section{Clinical Summary}

There were 10 male and 13 female patients, aged 3 to 32 years (mean age, 14 years). Patients were in New York Heart Association

\footnotetext{
From the Department of Cardiovascular Surgery, Cardiovascular Institute, Fu Wai Hospital, Chinese Academy of Medical Science, Peking Union Medical College, Beijing, China.

Received for publication Feb 26, 2001; accepted for publication April 9, 2001.

Address for reprints: Qingyu Wu, MD, Department of Cardiovascular Surgery, Cardiovascular Institute, Fu Wai Hospital, A 167 Beilishi Road, Fuchengmenwai, Beijing 100037, China (E-mail: WuQingyu@pulic.Bta.Net.cn).

J Thorac Cardiovasc Surg 2001;122:1237-8

Copyright (C) 2001 by The American Association for Thoracic Surgery

$0022-5223 / 2001 \$ 35.00+0 \quad \mathbf{1 2 / 5 4 / 1 1 6 4 6 3}$

doi:10.1067/mtc.2001.116463
}

functional class II $(\mathrm{n}=12)$ or III $(\mathrm{n}=11)$. The cardiothoracic ratio ranged from 0.50 to 0.73 (mean, 0.65). Tricuspid incompetence was moderate in 10 and severe in 13 patients. According to the operative inspections, 2 patients were classified as having Carpentier type A, 3 type B, and 18 type C.

Most of the atrialized chamber was excised, and the cut edges were sutured with 4-0 polypropylene sutures. Meanwhile, the tricuspid anulus was plicated. The displaced posterior and septal leaflets, with their chordae tendineae and papillary muscles, were detached from the anulus and the ventricular wall, modified, and joined together to produce new leaflets. The newly produced leaflets were reattached to the plicated anulus, and the papillary muscles were reimplanted in an appropriate position. In 5 patients the septal leaflet was severely hypoplastic, with the appearance of membranous remnants. A piece of fresh autologous pericardium was sutured to the near-normal septal anulus level. The chordae transferred from the anterior leaflet or made by clipping membranous remnants were sutured to the free edge of the pericardium to make a new septal leaflet (Figures 1 and 2). Associated procedures included 1 Rastelli operation, 6 cases of atrial septal defect repair, 4 cases of patent foramen ovale closure, 2 cases of ven- 


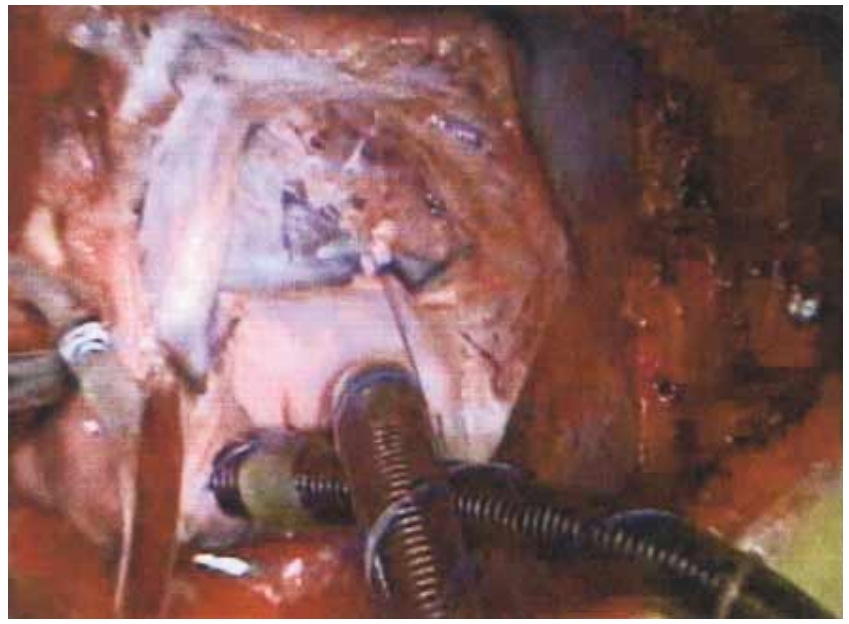

Figure 1. Chordae made by clipping membranous remnants.

tricular septal defect repair, and 1 case of division of a patent ductus arteriosus.

All patients survived and recovered uneventfully; their New York Heart Association functional class improved to class I. Postoperative echocardiography showed that tricuspid incompetence disappeared in 19 and was mild in 4 patients, the displaced tricuspid leaflets were near their normal level, the right ventricle was reduced in size remarkably, and the atrialized chamber vanished. In our follow-up study (range, 1-27 months; mean, 12 months), excise tolerance improved to normal, all patients were in sinus rhythm, and none had complete atrioventricular block. Echocardiography indicated that tricuspid incompetence disappeared in 19 and was mild in 4 patients.

\section{Discussion}

The proposed technique of treating Ebstein anomaly differs from previous techniques in some important ways. First, the atrialized chamber is excised longitudinally. Therefore, the right ventricular geometry is nearly restored, and the anatomic atrialized chamber is completely obliterated.

Second, a trileaflet valve is created, whereas in the techniques of Danielson, ${ }^{1}$ Hetzer, ${ }^{2}$ Vargas, ${ }^{3}$ and their colleagues, the anterior leaflet functions as a monocusp valve, and in the techniques of Carpentier, ${ }^{4}$ Quaegebeur, ${ }^{5}$ and their coworkers, the anterior leaflet and posterior leaflet function as a bileaflet valve. Whether it is monocusp or bileaflet, it is not the true anatomic structure of a tricuspid valve.

Third, there is almost no possibility for the tricuspid anulus to enlarge after annuloplasty because of the effective plication of the tricuspid anulus and competence of valve function and lightening of right ventricle pressure, and therefore the reconstructed tricuspid anulus was not reinforced with a prosthetic ring in any patient.

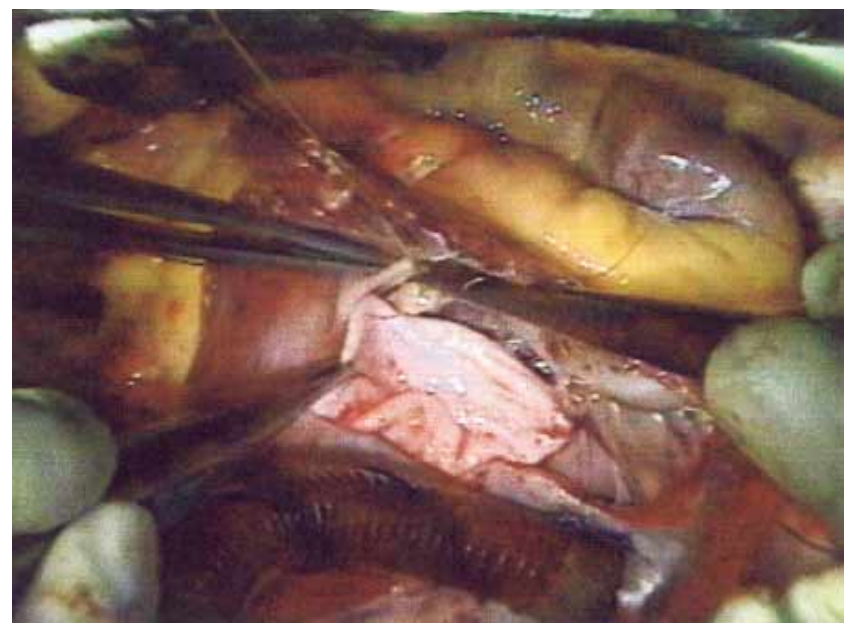

Figure 2. Autologous pericardium was sutured at near-normal septal anulus level. Chordae made by clipping membranous remnants was sutured to the free edge of the pericardium to make a new septal leaflet.

We think that the rigid tricuspid ring may reduce right ventricular function.

Because of complete excision of the atrialized chamber, a trileaflet mechanism covering the entire orifice area of the tricuspid valve, and restoration of the tricuspid anulus to its appropriate position and size at the atrioventricular junction, the valve function is competent. The incidences of right ventricular dysfunction and arrhythmia decrease, and a satisfactory result is achieved. The majority of patients with Ebstein anomaly could be free of tricuspid valve replacement. The indications for the conservative procedure have expanded. Long-term results require further observation.

\section{References}

1. Danielson GK, Driscoll DJ, Mair DD, Warnes CA, Oliver WC Jr. Operative treatment of Ebstein anomaly. J Thorac Cardiovasc Surg. 1992;104:1195-202.

2. Hetzer R, Nagdyman N, Ewert P, Weng YG, Alexi-Meskhisvili V, Berger F, et al. A modified repair technique for tricuspid incompetence in Ebstein anomaly. J Thorac Cardiovasc Surg. 1998;115:85768.

3. Vargas FJ, Mengo G, Granja MA, Gentile JA, Rannzini ME, Vazquez JC. Tricuspid annuloplasty and ventricular plication for Ebstein malformation. Ann Thorac Surg. 1998;65:1755-7.

4. Carpentier A, Chauvaud S, Mace L, Relland J, Mihaileanu S, Marino JP, et al. A new reconstructive operation for Ebstein anomaly of the tricuspid valve. J Thorac Cardiovasc Surg. 1988;96:92-101.

5. Quaegebeur JM, Sreenam N, Fraser AG, Bogers AJ, Stumper OF, Hess J, et al. Surgery for Ebstein anomaly: the clinical and echocardiographic evaluation of a new technique. J Am Coll Cardiol. 1991;17:722-8. 